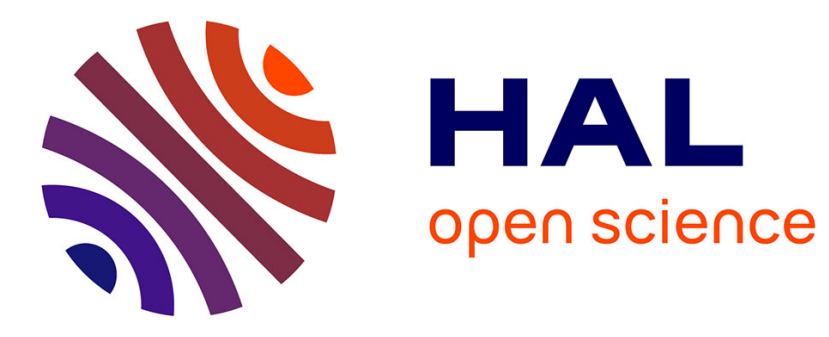

\title{
Use of Numerical Simulation to Predict Iliac Complications During Placement of an Aortic Stent Graft
}

Anne Daoudal, Juliette Gindre, Florent Lalys, Moundji Kafi, Claire Dupont, Antoine Lucas, Pascal Haigron, Adrien Kaladji

\section{To cite this version:}

Anne Daoudal, Juliette Gindre, Florent Lalys, Moundji Kafi, Claire Dupont, et al.. Use of Numerical Simulation to Predict Iliac Complications During Placement of an Aortic Stent Graft. Annals of Vascular Surgery, 2019, 61, pp.291-298. 10.1016/j.avsg.2019.04.035 . hal-02280248

HAL Id: hal-02280248

https://hal-univ-rennes1.archives-ouvertes.fr/hal-02280248

Submitted on 21 Dec 2021

HAL is a multi-disciplinary open access archive for the deposit and dissemination of scientific research documents, whether they are published or not. The documents may come from teaching and research institutions in France or abroad, or from public or private research centers.
L'archive ouverte pluridisciplinaire HAL, est destinée au dépôt et à la diffusion de documents scientifiques de niveau recherche, publiés ou non, émanant des établissements d'enseignement et de recherche français ou étrangers, des laboratoires publics ou privés.

\section{(ㄷ)(1) $\$$}

Distributed under a Creative Commons Attribution - NonCommerciall 4.0 International 


\section{USE OF NUMERICAL SIMULATION TO PREDICT ILIAC 2 COMPLICATIONS DURING PLACEMENT OF AN AORTIC 3 STENT GRAFT}

4 Anne Daoudal ${ }^{1,2,3} \mathrm{MD}$, Juliette Gindre ${ }^{2,3} \mathrm{PhD}$, Florent Lalys ${ }^{4} \mathrm{PhD}$, Moundji Kafi ${ }^{2,3} \mathrm{MSc}$,

5 Claire Dupont ${ }^{2,3} \mathrm{PhD}$, Antoine Lucas ${ }^{1,2,3} \mathrm{MD}$, Pascal Haigron ${ }^{2,3} \mathrm{PhD}$, Adrien Kaladji ${ }^{1,2,3}$ MD-

$6 \mathrm{PhD}$

1. CHU Rennes, Centre of Cardiothoracic and Vascular surgery, F-35033, Rennes, France

2. INSERM, U1099, F-35000 Rennes, France

3. University Rennes 1, Signal and Image Processing Laboratory (LTSI), F-35000 Rennes, France

4. Therenva, F-35000, Rennes, France

Corresponding author:

Adrien Kaladji, Centre of cardiothoracic and vascular surgery, University hospital of Rennes, F-35033 Rennes, France

Article category: original article

Short title: Numerical simulation and EVAR procedures

Total word count: 2906 words 


\section{Abstract}

22

\section{Objective}

During endovascular aneurysm repair (EVAR), complex iliac anatomy, is a source of complications such as unintentional coverage of the hypogastric artery. The aim of our study was to evaluate ability to predict coverage of the hypogastric artery using a biomechanical model simulating arterial deformations caused by the delivery system.

\section{Methods}

The biomechanical model of deformation has been validated by many publications. The simulations were performed on 38 patients included retrospectively, for a total of 75 iliac arteries used for the study. On the basis of objective measurements, two groups were formed: one with "complex" iliac anatomy ( $\mathrm{n}=38$ iliac arteries), the other with "simple" iliac anatomy ( $n=37$ iliac arteries). The simulation enabled measurement of the lengths of the aorta and the iliac arteries once deformed by the device. Coverage of the hypogastric artery was predicted if the deformed renal/iliac bifurcation length (Lpre) was less than the length of the implanted device (Lstent-measured on the post-operative CT) and non-deformed Lpre was greater than Lstent.

\section{Results}

Nine $(12 \%)$ internal iliac arteries were covered unintentionally. Of the coverage attributed to peri-operative deformations, 1 case $(1.3 \%)$ occurred with simple anatomy and $6(8.0 \%)$ with complex anatomy $(\mathrm{p}=0.25)$. All cases of unintentional coverage were predicted by the simulation. The simulation predicted hypogastric coverage in 35 cases (46.7\%). There were therefore 26 (34.6\%) false positives. The simulation had a sensitivity of $100 \%$ and a specificity of $60.6 \%$. On multivariate analysis, the factors significantly predictive of coverage 
44 were the iliac tortuosity index $(\mathrm{p}=0.02)$, the predicted margin between the termination of the

45 graft limb and the origin of the hypogastric artery in non-deformed $(\mathrm{p}=0.009)$ and deformed $46 \quad(\mathrm{p}=0.001)$ anatomy.

\section{Conclusion}

48 Numerical simulation is a sensitive tool for predicting the risk of hypogastric coverage during

49 EVAR and allows more precise pre-operative sizing. Its specificity is liable to be improved by 50 using a larger cohort.

51 


\section{INTRODUCTION}

The widespread uptake of endovascular aneurysm repair (EVAR) for abdominal aortic aneurysms (AAAs) has given rise to complications specific to this technique. The most wellknown complications are those that occur a while after the surgical procedure, such as endoleaks. However, there are some complications that can occur during the procedure itself and are independent of both the technique employed and the surgeon. These are complications specifically linked to use of stent grafts for treating aortic disease, given that such procedures attempt to achieve the closest fit possible between the patient's anatomy and the implanted device. In the last few years, planning tools such as sizing software have advanced considerably, providing several reconstructions and advanced measurements that permit a better appreciation of the patient's anatomy and hence optimization of device selection and the operative strategy to use.

Currently, complex anatomy represents the primary challenge for stent graft treatments given that the size of the eligible patient population is only limited by anatomy. Complex anatomy is problematic not only for the durability of the seal but also because, during the procedure, the rigid ancillary tools required to implant the stent graft cause some degree of anatomical deformation, which can modify the anatomy as perceived, or even precisely measured, before the procedure and as used to select the device to implant.

More specifically, the anatomy of the iliac arteries is highly variable between patients, with features such as calcification, tortuosity and angulation, which can also be present together. These arteries are subject to the greatest stress when the stent graft is placed (1) and can give rise to specific complications such as unintentional coverage of the internal iliac artery — this complication illustrates the above-mentioned paradox: although pre-operative anatomy is studied in detail to allow optimal selection of the stent graft, there are no specific tools 
available with which to predict the behavior of the landing zones, particularly when the stent

77 graft is definitively delivered.

78 In previous work $(2,3)$, we showed that a numerical finite element simulation enabled 79 quantification and localization of peri-operative deformations and, after comparing pre80 operative and actual, peri-operative data in 28 patients, we could conclude that we had a 81 reliable and validated biomechanical model for predicting peri-operative deformation. The 82 aim of the present study was to evaluate the predictive performance of this model with regard 83 to unintentional coverage of the internal iliac artery during placement of an aortic stent graft 84 in the treatment of AAA. 


\section{MATERIALS AND METHODS}

The protocol and informed consent form were approved by the local institutional review board, and all subjects gave informed consent. This was a retrospective study that compared the anatomy of iliac arteries defined in two groups: "simple anatomy" vs. "complex anatomy". Each iliac was considered as a specific case. Iliac arteries were assigned to one of these two groups on the basis of their anatomic complexity, as determined using the Society for Vascular Surgery's severity grading system (4), described below.

\section{Analysis of pre-operative CT scan and definition}

\section{Measurements used to categorize patients}

For each patient, the centerlines of the vasculature were extracted from the pre-operative CT scan (EndoSize®; Therenva, France). Pre-operative CT data were analyzed and the following variables were calculated in order to describe pre-operative iliac morphology and to use the SVS grading system:

- Iliac tortuosity index: the ratio between the length as measured by the centerline and the length of the shortest, straight-line path

- Maximal iliac angulation: measured using a 3D reconstruction

- Percentage of iliac calcification: determined using a specific measuring tool based on grayscale values of the Hounsfield scale (5)

A severity grade of 0 to 3 was assigned to each calculated value, as per Chaikof's standards. Measurements used to test simulation performance

The distance between the lowest renal artery and the ostium of the internal iliac artery measured using the centerline was called $\mathrm{L}_{\text {pre. }}$ This length corresponded to the maximum 
theoretical deployment zone of the stent graft without coverage of collaterals (renal or internal iliac arteries).

\section{Analysis of post-operative CT scan}

Centerlines were also extracted, with the stent graft in place, from the post-operative CT scan at 1 month. The first measurement, $\mathrm{L}_{\text {post, }}$ was the length from the lowest renal artery to the ostium of the internal iliac artery. The second measurement, $\mathrm{L}_{\text {stent, }}$ was the length from the lowest renal artery to the distal extremity of the graft limbs; this length corresponded to the length of the stent graft in situ.

\section{Group formation}

Patients were included in a non-interventional clinical research protocol, accepted by the institutional review board of Rennes University Hospital (April 2016) and the French national data protection agency (CNIL). Patients were included either prospectively (written consent obtained over a 12-month inclusion period) or retrospectively (a letter was sent to these patients and they did not provide written objection to retrospective participation in the study). All patients eligible for endovascular repair of an AAA with a 3rd-generation stent graft could be included. Patients who died or with intentional coverage of the internal iliac artery, decided pre-operatively, were excluded. Patients whose CT scans had a slice thickness greater than 1 $\mathrm{mm}$ and/or showed heterogeneous arterial enhancement of the aorta and the iliac arteries were not included. The selection of the stent graft was completely independent of the study, being entirely at the surgeon's discretion.

In order to achieve the same number of patients in both groups, the complex anatomy group was formed first. These patients had to have a severity grade of 2 or 3 for at least one of the three measured iliac variables for one or both of their iliac arteries. When a complex anatomy patient was selected, the next patient (in terms of the procedure date) was selected for the 
simple anatomy group if they fulfilled the criteria, namely a severity grade of 0 or 1 for the three measured iliac variables for both iliac arteries.

\section{Numerical simulation}

The modeling and simulation method used was described then validated in two previous publications using peri-operative data from 28 patients.

Using the simulation system, it was possible to model the configuration of the vascular tree deformed by the presence of rigid guide wires and the delivery system (using the patient's pre-operative CT scan). A simulation was performed for each patient, on the right then on the left sides. Next, the deformed vascular tree was analyzed in terms of centerline length. The renal-hypogastric length after insertions of the rigid guide wire and delivery system was measured on both sides: $\mathrm{L}_{\text {peri }}$. This length could then be compared to the implanted device in situ ( $\left.\mathrm{L}_{\text {stent }}\right)$.

\section{Prediction of residual length}

The post-operative residual length (length of uncovered iliac artery) was calculated as the difference between Lpost and Lstent and corresponded to the zone of the common iliac artery not covered by the stent graft. A negative value represented coverage of the internal iliac artery. The simulated residual length, computed from the model of the aorta deformed by the presence of the stent graft delivery system and rigid guide wire, was also computed. The postoperative residual length was analyzed by a statistical predictive model in order to identify the potential predictive variables from pre-operative anatomical and numerical simulation data.

\section{Prediction of internal iliac coverage}

The simulation predicted coverage of the internal iliac on the basis of two essential conditions: the deformed renal/iliac bifurcation length ( $\left.\mathrm{L}_{\text {peri }}\right)$ was less than the length of the 
155 implanted device ( $\mathrm{L}_{\text {stent }}$ ); and $\mathrm{L}_{\text {pre }}$ was greater than $\mathrm{L}_{\text {stent. }}$ If $\mathrm{L}_{\text {pre }}$ was less than $\mathrm{L}_{\text {stent }}$ and $\mathrm{L}_{\text {peri }}$ 156 less than $\mathrm{L}_{\text {stent}}$, then a sizing error had occurred (Figure 1).

\section{Statistical analysis}

158 The first analysis focused on the prediction of the post-operative residual length. Univariate 159 analyses were used to estimate the influence of pre-operative and simulation parameters.

160 Descriptive analysis and univariate analysis were performed using the $\chi 2$ test, Fisher's test, 161 Student's test or Pearson correlation, as appropriate. Parameters with a significance lower 162 than 0.2 were included in a multivariate analysis performed using multiple linear regression 163 and an iterative approach to select the best attributes.

164 The second analysis gave rise to a simple strategy for evaluation based on a pre-operative 165 simulation of risks. By focusing on the presence or absence of coverage (post-operative 166 residual length $<0$ ), the goal was to identify the subgroups of patients at high risk of 167 complications. The residual lengths predicted by simulating insertion of stiff tools were 168 directly used for risk stratification. The confusion matrices and ROC curves were thus 169 calculated using a threshold set at 0 for the estimated lengths.

170 Analyses were performed with the software program R (The R foundation for statistical 171 computing, 2009). 
174 The study included 38 patients (mean age: $77.8 \pm 8.1$ years). Given that one patient had 175 received an aortomonoiliac stent graft, a total of 75 iliac arteries were studied and simulated, 17666 of which $(88 \%)$ were from men. Thirty-seven and thirty-height iliac arteries (49.3\%) were 177 assigned to the simple and complex anatomy groups, respectively (Table 1). There were no significant differences in implanted stent grafts between groups (Table 2, $\mathrm{p}=0.065$ ).

\section{Prediction of post-operative residual length}

Parameters related to iliac anatomy and patient demographic data were included in the univariate analysis (Table 3), along with the pre-operative and simulated residual lengths. From the usual pre-operative anatomical and demographic variables, only the iliac angle score $(\mathrm{R}=0.33, \mathrm{p}=0.04)$ could predict the post-operative residual length. The simulated residual length showed higher predictive value $(\mathrm{R}=0.75, \mathrm{p}<0.001)$ than the pre-operative residual length $(\mathrm{R}=0.62, \mathrm{p}<0.001)$. In the multivariate analysis, four variables were shown to be significantly predictive: the pre-operative residual length $(\mathrm{p}=0.009)$, the simulated residual length $(\mathrm{p}=0.001)$, the tortuosity score $(0.0224)$ and the angulation score $(0.0587)$. There was a high correlation between the simulated and post-operative residual length (Figure 2).

\section{Prediction of internal iliac coverage}

Among the 75 iliac arteries, there were 9 cases (12\%) of unintentional internal iliac coverage, two of which were due to sizing error. Of the 7 cases attributed to peri-operative deformation, $1(1.3 \%)$ occurred in the simple anatomy group and $6(8.0 \%)$ in the complex anatomy group $(\mathrm{p}=0.25)$. After comparison of the real and simulated situations, there was a correspondence between simulated and real internal iliac coverage (Figure 3). All iliac arteries covered accidentally were also covered in the simulation. The sensitivity of the simulation was $100 \%$. 
196 The simulation predicted internal iliac coverage in 35 cases $(46.7 \%)$. Hence there were 26 197 (34.6\%) patients who had internal iliac coverage in the simulation but not in reality. The 198 specificity of the simulation was $60.6 \%$. Coverage of the internal iliac artery (yes/no) via the 199 difference in the residual length after insertion of the delivery system/length of the stent graft 200 in situ ( $\left.\mathrm{L}_{\text {post }}\right)$ was predicted with an area under the curve of 0.91 (Figure 4). 


\section{DISCUSSION}

203

204

205

206

207

208

209

210

In this article, we describe the use of simulation to predict a complication during the surgical procedure. The simulation models deformable anatomy (a property of soft tissues such as arteries) and its interactions with rigid materials. The current version of the numerical model focuses on the consequences of deformation during the aortic endovascular procedure, which are two-fold. First, by reducing arterial length, deformations have an impact on calibration. This illustrates the paradox of current practice whereby planning is based on an arterial volume that has different dimensions when the stent graft is deployed. This paradox is a source of complication and error. The exact quantification of deformation-related shortening is difficult and not based on statistical data. Coverage of internal iliac arteries is responsible for buttock claudication and even pelvic ischemia (6-9) so must be avoided at all costs, but it presents enormous planning challenges in complex anatomy. Such coverage could be related to a sizing error, as occurred with two patients included in the present study, but it is more often related to deformations of the aortoiliac vasculature caused by insertion of rigid material such as the rigid guide wire and the stent graft delivery system.

In our study, we set ourselves the task of predicting the residual length of the common iliac artery, i.e. the length not covered by the stent graft, because it is one of the variables that every surgeon intuitively attempts to control for when choosing the length of the stent graft to implant. To achieve a realistic model, we decided to determine the length of the stent graft on the basis of the post-operative CT scan rather than using the value in the catalog. There is indeed a difference between catalog length and in situ length. Our study showed that no single anatomical variable is able to predict the post-operative residual length without the aid of simulation. The most predictive variable was the residual margin between the extremity of the graft limb and the ostium of the internal iliac, in an aorta deformed by the stent graft delivery 
system. This result highlights the utility of simulation when planning EVAR. Finally, in this study of a highly specific clinical complication — coverage of the internal iliac — the results showed that simulation alone is capable of predicting this risk with a robust model (ROC curve). The clinical relevance of this study was to predict coverage of the internal iliac artery. All cases of unintentional coverage were predicted by the numerical simulation. In clinical practice, this simulation model could play an important role in reducing iliac complications during EVAR procedures.

Whittaker et al. (10) proposed an algorithm to predict the length of the stent graft modified during the EVAR procedure; however their model was based on pre- and post-operative CT data, whereas peri-operative data are more precise for preventing and predicting perioperative complications. Iliac tortuosity is known to be a source of complications during or after EVAR and represents a difficult aspect of the procedure. In our previous works $(2,3)$, we showed that the reliability of our model extended to complex cases. Conformation of aortic stent grafts has already been studied by comparing in vitro or in vivo models with a numerical simulation (11-13), and it was shown that stent graft behavior could be anticipated from the anatomy, notably in cases of complex anatomy.

The second consequence of deformation during EVAR procedures concerns the precision of rigid registration in fusion imaging. It is currently accepted in several articles $(1,14)$ that deformation represents the leading source of registration error when the pre-operative CT scan is laid over the 2D fluoroscopic image. It is the primary factor limiting fusion imaging. With the aid of a numerical deformation model, the precision of fusion can be improved, helping to achieve precise positioning of the graft limbs (Figure 5). 
Another approach to gain precision would be to perform intra-operative length measurements, using for instance a calibrated pigtail catheter after the introduction of stiff guide-wire, and integrate these data into new predictive models or refine previous ones.

Our study has several limitations. The number of patients is small; it is probable that a greater number of patients would improve the robustness of the model (its specificity, among other aspects). The incidence of complex anatomy was low and we were not able to include more patients from our center fulfilling the study criteria. There may also be a selection bias, as patients with too complex iliac anatomy could have undergone open surgery. However, at our center, since the emergence of 3rd-generation stent grafts, iliac access has not been a contraindication to EVAR, with the exclusion of iliac occlusion. At our center, contraindications to EVAR only concern the proximal neck (length $<10 \mathrm{~mm}$ ). Improvements in the profile of stent grafts have allowed procedures with stenosed and tortuous access vessels, sometimes with additional steps such as paving and cracking when applicable. This is why we did not retrospectively include patients at our center treated with 2 nd-generation stent grafts. Complex anatomy therefore represents a veritable clinical challenge. Obviously, there are solutions for better appreciating deformations, for example taking peri-operative iliac measurements using graduated markings on the rigid guide wire, but this technique carries with it the risk of parallax error, which is greater with tortuous iliac arteries.

One unresolved issue, whose existence provides the impetus for us to continue working on numerical simulation, is the behavior of the iliac artery after delivery of the stent graft and withdrawal of the rigid guide wire. In our practice, we have observed that sometimes the anatomy (even sometimes tortuous anatomy) reverts to its initial form and sometimes it does not. This behavior is multifactorial and probably difficult to predict because it also depends on the implanted stent graft and its biomechanical characteristics. Our simulation model should therefore simulate delivery of the stent graft, and take into account the overlapping of 
273 different modules and the different brands of stent graft. Reaching this point requires a 274 significant technical and scientific leap forward. This is why we initially decided that data 275 from deformation by one guide wire and one delivery system were sufficient to develop a 276 reliable, robust and precise tool for predicting peri-operative arterial behavior. Other 277 applications under study include the displacement of ostia of renal and gastrointestinal arteries 278 during placement of a fenestrated stent graft, which poses problems, not only for sizing, but 279 also for peri-operative positioning of the stent graft and catheterization. Transfer to other 280 centers remains a problem. However it is possible to simplify the model without sacrificing 281 precision so that it becomes less time-consuming to use and can be integrated into sizing 282 programs used routinely in clinical practice.

\section{CONCLUSION}

284 Evaluation of surgical risk is a constant concern for surgeons. Numerical simulation provides

285 precise information about arterial biomechanical behavior during implantation of an aortic 286 stent graft. Complex anatomy is associated with a higher incidence of peri-operative iliac 287 complications due to deformation. Simulation models deformations and could provide 288 quantitative information that would reduce the risk of complications.

\section{Acknowledgments}

290 This work has been partially conducted in the experimental platform TherA-Image (Rennes,

291 France) supported by Europe FEDER. This study has been partially supported by the French

292 National Research Agency (ANR) in the context of the Endosim project (grant $\mathrm{n}^{\circ}$ ANR-13TECS-0012). 


\section{REFERENCES}

1. Kaladji A, Dumenil A, Castro M, Cardon A, Becquemin J-P. Prediction of deformations during endovascular aortic aneurysm repair using finite element simulation. Comput Med Imaging Graph. 2013;

2. Gindre J, Bel-Brunon A, Rochette M, Lucas A, Kaladji A, Haigron P, et al. PatientSpecific Finite-Element Simulation of the Insertion of Guidewire During an EVAR Procedure: Guidewire Position Prediction Validation on 28 Cases. IEEE Trans Biomed Eng. mai 2017;64(5):1057-66.

\section{Gindre J, Bel-Brunon A, Kaladji A, Duménil A, Rochette $M$, Lucas A, et al. Finite} element simulation of the insertion of guidewires during an EVAR procedure: example of a complex patient case, a first step toward patient-specific parameterized models. Int J Numer Methods Biomed Eng. juill 2015;31(7):e02716.

4. Chaikof EL, Fillinger MF, Matsumura JS, Rutherford RB, White GH, Blankensteijn JD, et al. Identifying and grading factors that modify the outcome of endovascular aortic aneurysm repair. J Vasc Surg. mai 2002;35(5):1061-6.

5. Kaladji A, Vent P., Danvin A, Chaillou P, Costargent A, Guyomarch B, et al. Impact of Vascular Calcifications on Long Femoropopliteal Stenting Outcomes. Ann Vasc Surg. févr 2018;48:170-8.

6. Jean-Baptiste E, Brizzi S, Bartoli MA, Sadaghianloo N, Baqué J, Magnan P-E, et al. Pelvic ischemia and quality of life scores after interventional occlusion of the hypogastric artery in patients undergoing endovascular aortic aneurysm repair. J Vasc Surg. juill 2014;60(1):40-49.e1.

7. Pirvu A, Gallet N, Perou S, Thony F, Magne J-L. Midterm results of internal iliac artery aneurysm embolization. JMV-J Médecine Vasc. mai 2017;42(3):157-61.

8. Fujioka S, Hosaka S, Morimura H, Chen K, Wang ZC, Toguchi K, et al. Outcomes of Extended Endovascular Aortic Repair for Aorto-Iliac Aneurysm with Internal Iliac Artery Occlusion. Ann Vasc Dis. 2017;10(4):359-63.

9. Bosanquet DC, Wilcox C, Whitehurst L, Cox A, Williams IM, Twine CP, et al. Systematic Review and Meta-analysis of the Effect of Internal Iliac Artery Exclusion for Patients Undergoing EVAR. Eur J Vasc Endovasc Surg. avr 2017;53(4):534-48.

10. Whittaker DR, Dwyer J, Fillinger MF. Prediction of altered endograft path during endovascular abdominal aortic aneurysm repair with the Gore Excluder. J Vasc Surg. avr 2005;41(4):575-83. 
327 11. De Bock S, lannaccone F, De Santis G, De Beule M. Virtual evaluation of stent graft

328 deployment: A validated modeling and simulation study. J Mech Behav Biomed Mater. 2012;

329 12. Perrin D, Badel P, Orgeas L. Patient specific simulation of endovascular repair surgery

330 with tortuous aneurysms requiring flexible stentgrafts.pdf. journal of the mechanical

331 behavior of biomedical materials; 2016.

332 13. Perrin D, Badel P, Orgeas L. Patient specific numerical simulation of stentgraft

333 deployment validation on three clinical cases. journal of the mechanical behavior of

334 biomedical materials; 2016.

335 14. Duménil A, Kaladji A, Castro M, Göksu C, Lucas A, Haigron P. A versatile intensity-

336 based 3D/2D rigid registration compatible with mobile $C$-arm for endovascular treatment of

337 abdominal aortic aneurysm. Int J Comput Assist Radiol Surg. sept 2016;11(9):1713-29.

338

339 
341 Figure 1: Definition of prediction of coverage. Lpre is the renal- iliac length without

342 deformation, Lperi is the same length adjusted by simulation and after deformation, and

343 Lstent is the length of the stentgraft in situ measured on postoperative CT scan.

$344 \quad$ Figure 2

345 Prediction of the post-operative (real) residual length: calibration plot

$346 \quad$ Figure 3

347 Distribution of false positive (FP), true positive (TP), false negative (FN) and true negative

348 (TN), based on the post-operative (real) and simulated (predicted) residual length.

$349 \quad$ Figure 4

350 ROC curve using logistic regression

$351 \quad$ Figure 5

352 Application of simulation in endovascular navigation for fusion imaging. Fluoroscopic image

353 with the fusion of the 3D preoperative anatomy without deformation (A) and the same image

354 with deformation 


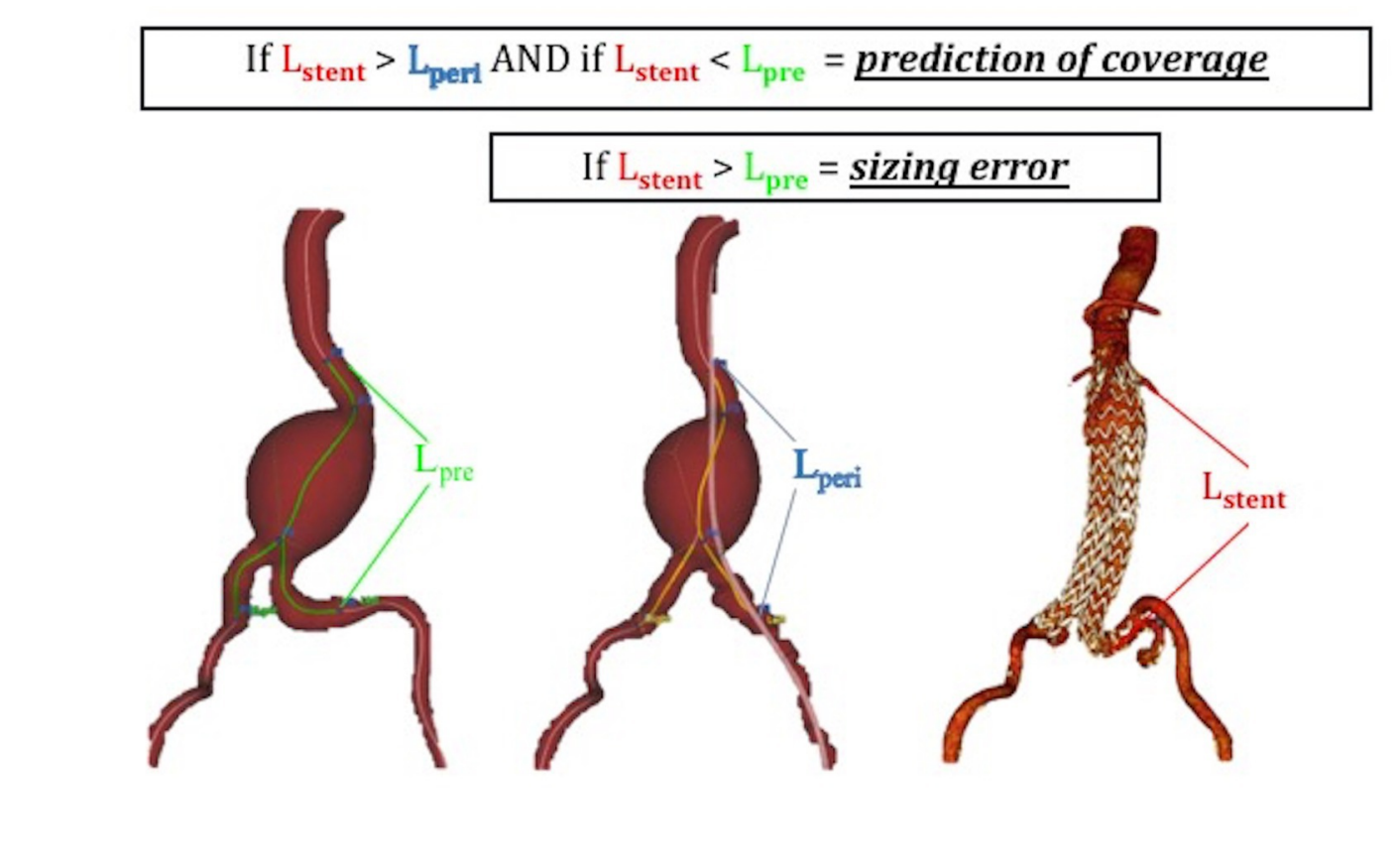




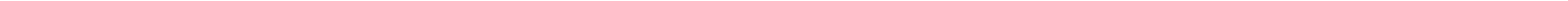




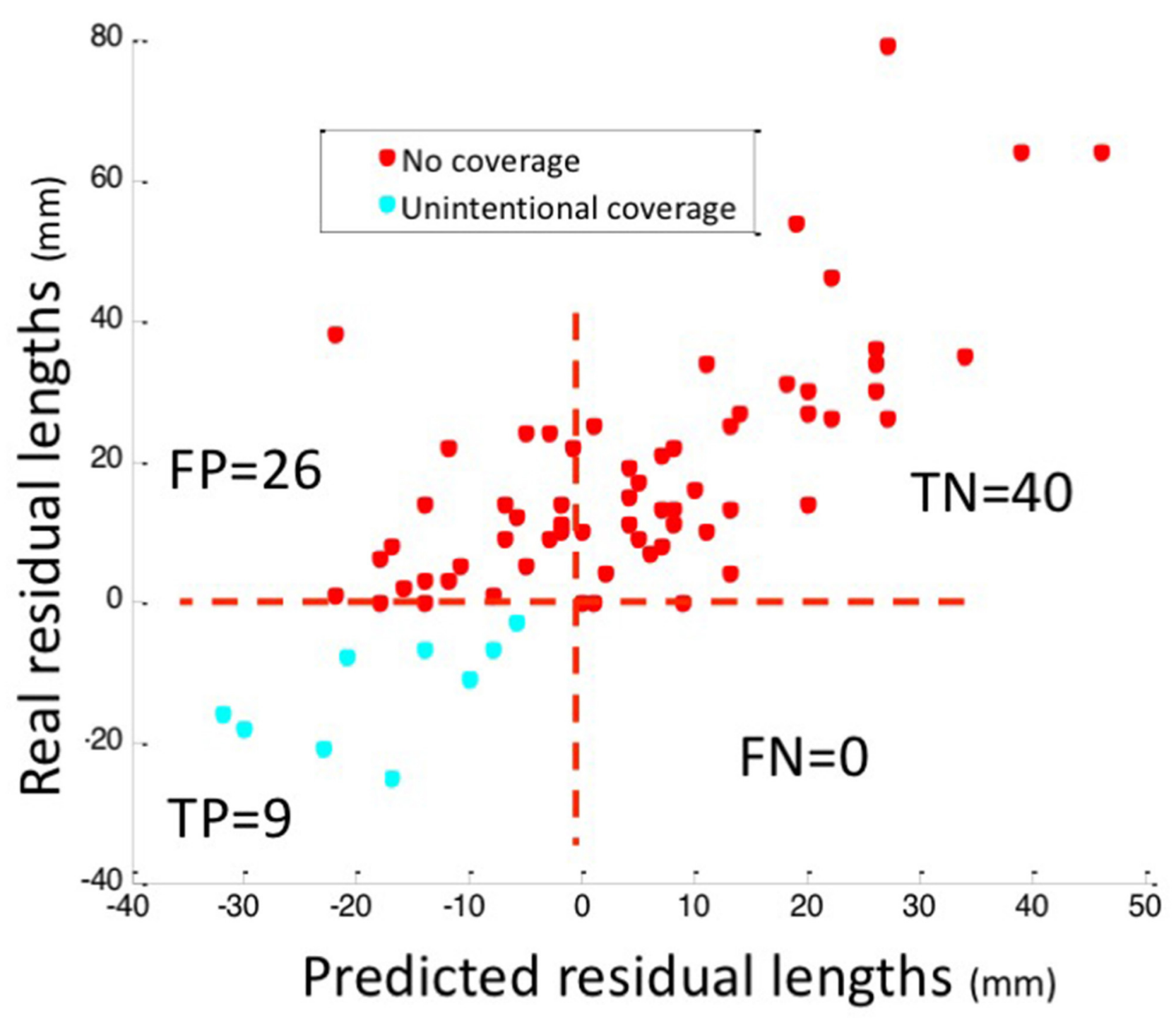




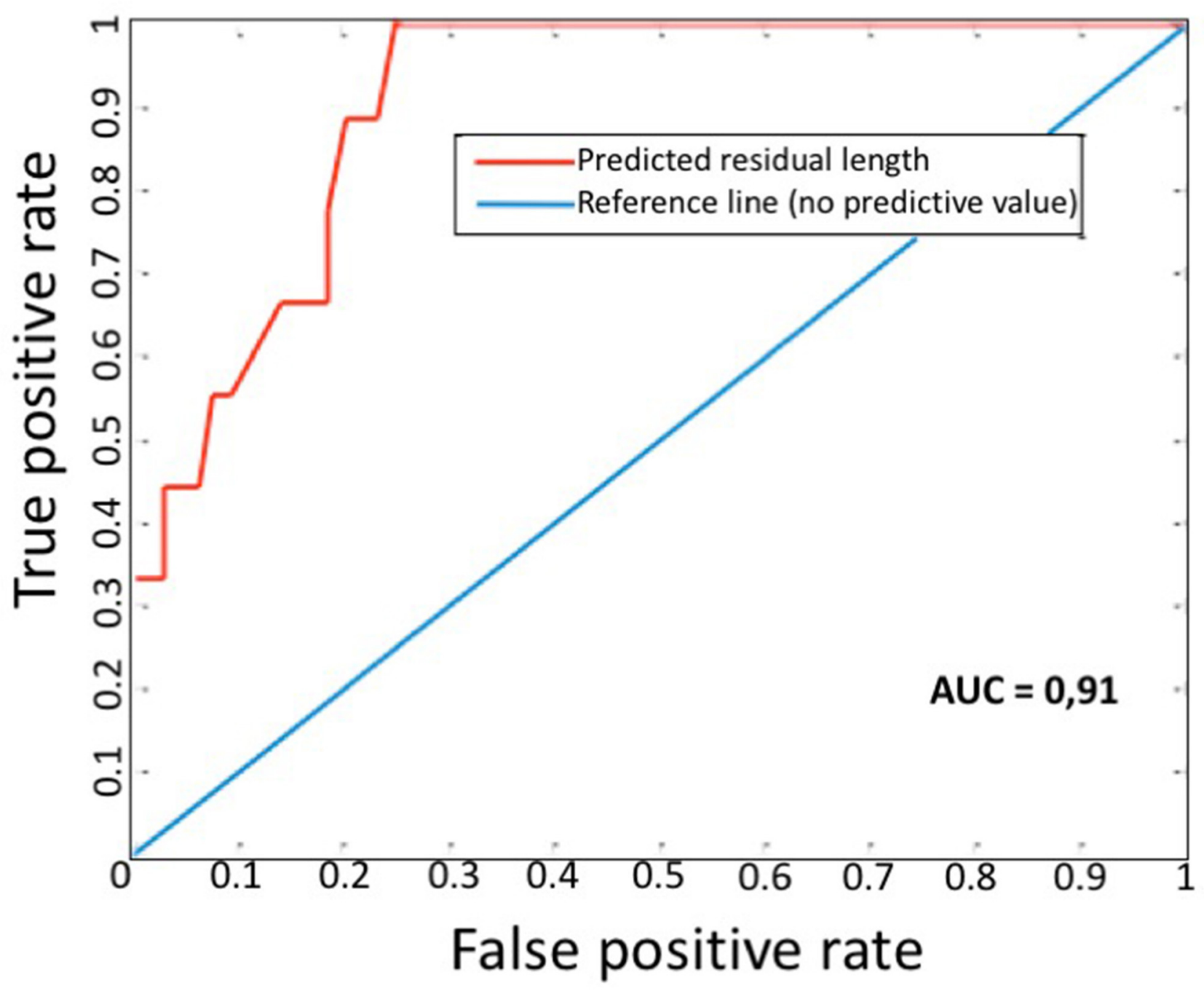


Table 1: Descriptive analysis: comparison of demographic and anatomical parameters between groups

\begin{tabular}{|c|c|c|c|}
\hline & $\begin{array}{c}\text { Simple anatomy } \\
(\mathrm{n}=37)\end{array}$ & $\begin{array}{c}\text { Complex anatomy } \\
(n=38)\end{array}$ & $p$ \\
\hline Pre-operative aorto-iliac length $(\mathrm{cm}$, mean $\pm \mathrm{SD})$ & $176.9 \pm 17.9$ & $194.6 \pm 21.2$ & $<0.01$ \\
\hline Age (Years, mean \pm SD ) & $77.1 \pm 8.2$ & $77.8 \pm 8.1$ & 0.45 \\
\hline Sex (male, number $(\%)$ ) & $31(83,8 \%)$ & $35(92,1 \%)$ & 0.15 \\
\hline Iliac tortuosity index (mean \pm SD) & $1.34 \pm 0.09$ & $1.54 \pm 0.17$ & $<0.01$ \\
\hline Tortuosity score (number (\%)) & & & $<0.01$ \\
\hline 0 (index $<1.25$ ) & $6(16.2 \%)$ & $2(5.3 \%)$ & \\
\hline $1(1.25<$ inde $x<1.5)$ & $31(83.8 \%)$ & $10(26.3 \%)$ & \\
\hline $2(1.5<$ index $<1.6)$ & $0(0 \%)$ & $14(36.8 \%)$ & \\
\hline 3 (index $>1.6$ ) & $0(0 \%)$ & $12(31.6 \%)$ & \\
\hline Maximal iliac angle $($ mean \pm SD) & $142 \pm 13.27$ & $107.58 \pm 19.83$ & $<0.01$ \\
\hline Iliac angle score (number $(\%)$ ) & & & $<0.01$ \\
\hline $0\left(160^{\circ}-180^{\circ}\right)$ & $3(8,1 \%)$ & $0(0 \%)$ & \\
\hline $1\left(121^{\circ}-159^{\circ}\right)$ & $34(91.9 \%)$ & $11(28.9 \%)$ & \\
\hline $2\left(90^{\circ}-120^{\circ}\right)$ & $0(0 \%)$ & $19(50 \%)$ & \\
\hline $3\left(<120^{\circ}\right)$ & $0(0 \%)$ & $8(21 \%)$ & \\
\hline Iliac calcifications $($ mean \pm SD) & $20 \% \pm 0.15$ & $16 \% \pm 0.14$ & $<0.01$ \\
\hline Calcification score (number $(\%)$ ) & & & $<0.01$ \\
\hline 0 (none) & $0(0 \%)$ & $4(10.5 \%)$ & \\
\hline 1 (<25\% vessel length) & $28(75.7 \%)$ & $26(68.4 \%)$ & \\
\hline $2(25 \%-50 \%$ vessel length ) & $7(18.9 \%)$ & $8(21.1 \%)$ & \\
\hline 3 (>50\% vessel length) & $2(5.4 \%)$ & $0(0 \%)$ & \\
\hline
\end{tabular}


Table 2: Repartition of the implanted stentgrafts according to groups

Cook - Zenith alpha Endologix - AFX Gore - Excluder C3 Medtronic - Endurant II

\begin{tabular}{lllll} 
Simple anatomy & 10 & 4 & 6 & 17 \\
Complex anatomy & 12 & 3 & 0 & 23 \\
Total & 22 & 7 & 6 & 40 \\
\hline
\end{tabular}


Table 3: Prediction of the post-operative residual length: univariate analysis.

\begin{tabular}{|c|c|c|}
\hline & $\begin{array}{c}\text { total } \\
(n=75)\end{array}$ & $p$ \\
\hline $\begin{array}{l}\text { Pre-operative aorto-iliac length }(\mathrm{cm}, \text { mean } \pm \\
\text { SD) }\end{array}$ & $185.9 \pm 21.4$ & 0.06 \\
\hline Age (Years, mean \pm SD ) & $77.4 \pm 8.1$ & 0.57 \\
\hline Sex (male, number (\%)) & $66(88 \%)$ & 0.34 \\
\hline Iliac tortuosity index $($ mean \pm SD) & $1.44 \pm 0.17$ & 0.73 \\
\hline Tortuosity score (number (\%)) & & 0.09 \\
\hline 0 (index $<1.25$ ) & $8(10.7 \%)$ & \\
\hline $1(1.25<$ index $<1.5)$ & $41(54.7)$ & \\
\hline $2(1.5<$ index $<1.6)$ & $14(18.7 \%)$ & \\
\hline 3 (index $>1.6$ ) & $12(16 \%)$ & \\
\hline Maximal iliac angle $($ mean \pm SD) & $125 \pm 24.27$ & 0.12 \\
\hline Iliac angle score (number (\%)) & & 0.04 \\
\hline $0\left(160^{\circ}-180^{\circ}\right)$ & $3(4 \%)$ & \\
\hline $1\left(121^{\circ}-159^{\circ}\right)$ & $45(60 \%)$ & \\
\hline $2\left(90^{\circ}-120^{\circ}\right)$ & $19(25.3 \%)$ & \\
\hline $3\left(<120^{\circ}\right)$ & $8(10.7 \%)$ & \\
\hline Iliac calcifications $($ mean \pm SD) & $18 \% \pm 0.15$ & 0.51 \\
\hline Calcification score (number $(\%)$ ) & & 0.35 \\
\hline 0 (none) & $4(5.3 \%)$ & \\
\hline 1 (<25\% vessel length) & $54(72 \%)$ & \\
\hline $2(25 \%-50 \%$ vessel length) & $15(20 \%)$ & \\
\hline 3 (>50\% vessel length) & $2(2.7 \%)$ & \\
\hline Pre-operative residual length* & $24.5 \pm 19.9$ & $<0.01$ \\
\hline Simulated residual length** & $0.5 \pm 17.9$ & $<0.01$ \\
\hline
\end{tabular}

* Difference between Lpre and Lstent

** Difference between Lperi and Lstent 